\title{
Transformative placemaking
}

\section{Lourdes Torres ${ }^{1}$}

Published online: 7 May 2020

(c) Springer Nature Limited 2020

How do we make the spaces we inhabit livable? When placemaking is a collective process, it has the potential to bring people together to imagine and forge communities that can nurture and sustain us now and in the future. Such placemaking is a collaborative endeavor inspired by a community's capacious dreams, diverse strengths, and openness to an evolving process. The articles in this issue invite us to think about how Latinos make a place for themselves in and across settings and situations.

Gerardo Francisco Sandoval and Shawn J. Rodine focus on immigrant integration and placemaking in rural Oregon. To supplement their income and create more livable spaces there, Mexican farmers are setting up small farms modeled on the ranchitos they inhabited back home. Bypassing official integration mechanisms, these informal businesses, which engage in environmentally sustainable practices, demonstrate how Mexican immigrants are transforming rural communities in Oregon as they reimagine aspects of their traditional ways in a new setting.

Similarly, Jennifer Bickham Mendez and Natalia Deeb-Sossa help us understand how immigrant mothers in two different communities-one a longtime setting for immigrants, the other a more recent destination-work to stake a claim in the United States. Their comparative analysis of Latina immigrant mothers' experiences in a farmworker community in Northern California, and in a revitalized small town in Williamsburg, Eastern Virginia, demonstrates how women with few economic resources strategize to forge a future for themselves and their families. Despite concerns about immigration status, they organize themselves, seek allies wherever they can, and make their voices heard. Whether advocating for housing or for educational services for their children, these determined women use all available resources to secure the health and well-being of their families.

Cynthia Martínez follows with an analysis of performativity and placemaking in the literary writings of two immigrant authors with roots in Peru. According to Martínez, Marie Arana and Braulio Muñoz explore a range of cultural, racial, and ethnic identities as they struggle to make sense of themselves and attempt to make themselves legible across sites in Peru and the United States. Disrupting ideals of national homogeneity, the main characters in Arana's American Chica and Muñoz's

Lourdes Torres

ltorres@depaul.edu

1 DePaul University, Chicago, IL, USA 
The Peruvian Notebooks embrace and experiment with shifting identities as they fashion places for themselves across transnational settings.

Justin Torres burst onto to the literary scene in 2012 with We the Animals, a provocative novel featuring a queer mixed-race Puerto Rican protagonist who navigates the difficult terrain between Latinx and queer identities as he comes of age. Zorimar Rivera Montes claims We the Animals offers a blueprint for Latinx queer liberation. She argues that Torres uses a strategy of opacity, "the refusal to be legible to the gaze of a dominant Other," to explore questions of Latinidad, sexuality, gender and ethnic identities.

Speaking of placemaking, we are pleased to offer a special section, A Tribute to Frances Aparicio, in this issue, recognizing the legacy of Frances Aparicio, founder of this journal, who dedicated her career to carving a space in academia for our field. Across her illustrative career, Frances had been a tireless advocate both for Latino studies and for the many scholars who continue to toil in her footsteps. We offer this tribute to Frances Aparicio on the occasion of her retirement. The essays in this special section, all by former students who are now themselves major figures in multiple interdisciplinary fields, make evident the vast influence Frances has had across fields and, more significantly, in the lives of her many students. I love that these thoughtful and moving essays not only laud Frances for her significant research, teaching, and mentoring contributions but also exemplify her continuing impact and relevance through the cutting-edge projects her students continue to produce.

Following the special section, we offer a poignant essay by Richard T. Rodriguez reminding us that vibrant queer spaces exist beyond the city and deserve to be acknowledged and celebrated. Finally, we share an inspiring reflection by Anahí Viladrich presenting innovative strategies for teaching in challenging times.

Be sure to check out the book reviews that round out this issue.

Enjoy!

Publisher's Note Springer Nature remains neutral with regard to jurisdictional claims in published maps and institutional affiliations. 